\title{
Potencial de recuperação de recicláveis em um condomínio residencial de grande porte de São Caetano do Sul
}

\author{
Recovery potencial of recyclables at a large \\ residential condominium in São Caetano do Sul
}

Renée Alvim de Freitas Rodrigues Pinto', Giulliana Mondelli²

\begin{abstract}
RESUMO
Este trabalho tem como objetivo avaliar o potencial de recuperação de resíduos recicláveis de um condomínio residencial vertical de grande porte localizado no município de São Caetano do Sul (SP). Foi realizado o diagnóstico da gestão de resíduos e da infraestrutura do condomínio, bem como foram feitas entrevistas com o Conselho Diretivo do condomínio e com o instituto responsável pela triagem dos resíduos, eaplicados questionários aos moradores. O principal desafio foi a frequência e a adequabilidade na comunicação interna e sensibilização, tanto de residentes como dos funcionários domésticos. Entre os aspectos favoráveis, identificou-se a comodidade para descarte dos recicláveis para os moradores; e condições favoráveis para a comercialização dos recicláveis, como presença de local adequado para armazenamento de recicláveis segregados, elevado volume de recicláveis gerados e mercado favorável na região para a comercialização dos materiais. Foi verificado que são recuperados 13,7\% da totalidade de recicláveis presentes nos resíduos domiciliares. Conforme o presente estudo, verificou-se ainda que a coleta seletiva de resíduos sólidos domiciliares em condomínios é vulnerável, dado à falta de consistência de ações efetivas de divulgação e mobilização, bem como de decisões da administração local.
\end{abstract}

Palavras-chave: coleta seletiva; resíduos sólidos urbanos (RSU); melhoria contínua.

\begin{abstract}
This paper aims at evaluating the potential recovery of recyclable materials at a large vertical residential condominium located in the municipality of São Caetano do Sul, state of São Paulo, Brazil. A survey on the waste management and the building facilities was conducted. Interviews with the governing board of the condominium and with the institute responsible for segregating recyclables were carried out, together with questionnaires applied to residents. The main challenge during this survey was the frequency and quality of internal communication for information and awareness, including both residents and respective domestic staff. As positive aspects, the convenience for disposal of recyclables by the residents; favorable conditions for the recyclables market, and presence of suitable location for storing segregated recyclables at the condominium were identified. It was found that the recovered materials were $13.7 \%$ of all recyclables present in domestic waste. This study showed that the selective collection of solid waste in residential condominiums is vulnerable owing to the lack of effective promoting and mobilization actions, as well lack of local administration decisions.
\end{abstract}

Keywords: selective collection; municipal solid waste (MSW); continuous improvement.

\section{INTRODUÇÃO}

A crescente urbanização no Brasil tem tornado a vida em condomínios verticais uma tendência nos grandes centros urbanos. Segundo o Compromisso Empresarial para Reciclagem - CEMPRE (2010), o processo de concentração da população vem ocorrendo desde 1950 devido aos mais variados fatores, como migração interna, mecanização da agricultura, processo de industrialização, busca por melhores oportunidades de empregos, qualidade de vida, entre outros.
Com o estímulo cada vez maior ao consumo, normalmente por produtos de baixa durabilidade e com grande quantidade de embalagens, torna-se inevitável o aumento de volume, a diversificação e a concentração espacial da geração de resíduos sólidos. Segundo a Associação Brasileira de Empresas de Limpeza Pública e Resíduos especiais - ABRELPE, (2012), a geração de resíduos sólidos urbanos (RSU) no Brasil cresceu 1,3\% de 2011 para 2012, índice superior à taxa de crescimento populacional urbano, que foi de $0,9 \%$ no mesmo período. 
A Lei Federal no 12.305 (BRASIL, 2010), que estabelece a Política Nacional de Resíduos Sólidos (PNRS), em seu Artigo $3^{\circ}$ define como disposição final ambientalmente adequada a distribuição ordenada de rejeitos em aterros, observando normas operacionais específicas de modo a evitar danos ou riscos à saúde pública e à segurança e a minimizar os impactos ambientais adversos. Segundo a PNRS, resíduo sólido caracteriza-se como rejeito quando, depois de esgotadas todas as possibilidades de tratamento e de recuperação por processos tecnológicos disponíveis e economicamente viáveis, não apresente outra possibilidade que não a disposição final ambientalmente adequada, como aterros ou incineração.

A coleta seletiva é uma das principais ferramentas a serem utilizadas em termos de gerenciamento de resíduos sólidos, de acordo com a PNRS (BRASIL, 2010). Aterros que recebam apenas rejeitos, atualmente, não é a realidade dos municípios brasileiros. Segundo o Instituto de Pesquisa Econômica Aplicada - IPEA (2012), existe a perda de R 8 bilhões/ano em matérias-primas não aproveitadas por não ter sido feita a reciclagem.

A devida segregação de materiais na fonte, quando realizada adequadamente e de forma planejada, contribui para que apenas rejeitos sejam enviados para disposição, desonera custos de coleta e de triagem dos materiais recicláveis, sendo, portanto, um compromisso a ser atendido por todos. Segundo Moraes (2003), em relatório da Prefeitura do Município de São Paulo, em regiões onde o nível de verticalização é alto, a organização na separação de recicláveis é maior do que em regiões de baixa verticalização, em função da maior organização dos funcionários de condomínios e prédios comerciais. Tal constatação contribui para indicar as oportunidades existentes na segregação de recicláveis em sua fonte, especialmente em condomínios verticais.

Assim, torna-se cada vez mais necessária e relevante a concepção e o conjunto das atividades relacionadas ao empreendimento habitacional, em todo seu ciclo de vida, voltadas para a minimização dos impactos ambientais e a maximização de benefícios sociais, em conjunto com sua viabilidade econômica.

O Plano Municipal de Gestão Integrada de Resíduos Sólidos de São Caetano do Sul (SP), concluído em 2012, aponta diretrizes e estratégias para que somente rejeitos sejam encaminhados para disposição final. O programa de coleta seletiva para resíduos domiciliares secos, com sua gestão compartilhada entre Secretaria de Meio Ambiente e Sustentabilidade (SEMAS), Secretaria Municipal de Serviços Urbanos (SESURB) e Departamento de Água e Esgoto de São Caetano do Sul (DAE), atende aos 15 bairros do município com frequência de coleta de uma vez por semana, e todas as residências são atendidas em todo o território da cidade. Em 2013, aproximadamente $80 \%$ da população era atendida pela coleta porta-a-porta, considerando que o cadastramento dos condomínios estava sendo processado e $70 \%$ deles já estavam incluídos na coleta seletiva. Especificamente em relação às ações direcionadas aos condomínios, está o estabelecimento de regras para polos geradores (locais de grande geração) de resíduos sólidos, como condomínios residenciais, comerciais e mistos; elaboração de projeto-piloto de segregação de resíduos sólidos domiciliares (RDO) secos; estudo de acondicionamento para coleta; estudo do uso de contentores para resíduos secos e úmidos em novos empreendimentos imobiliários, como em condomínios já habitados; e determinação no Código de Obras do município de espaços físicos obrigatórios específicos para resíduos sólidos (úmidos e secos) (SÃO CAETANO DO SUL, 2013).

Sob a ótica do condomínio, os benefícios de padrões sustentáveis de gestão de resíduos sólidos são diversos e estão presentes tanto no bem-estar dos condôminos quanto em aspectos sanitários satisfatórios presentes nos locais, até mesmo na valorização do empreendimento, o qual passa a transmitir boas práticas de governança em sua administração (CBCS; SECOVI, 2011. Assim, os impactos positivos advindos dos resultados ambientais do gerenciamento adequado dos resíduos, além da otimização de recursos utilizados na operação, também podem contribuir positivamente com os resultados econômicos do empreendimento.

O presente trabalho busca avaliar o potencial existente de um condomínio estudado em São Caetano do Sul quanto à recuperação de recicláveis, bem como avaliar e propor melhorias em relação à gestão e à coleta seletiva.

\section{CARACTERIZAÇÃO DA ÁREA ESTUDADA}

A área de estudo abrange um condomínio de grande porte, com $48.000 \mathrm{~m}^{2}$ de área externa, localizado no município de São Caetano do Sul. O condomínio é constituído por 700 apartamentos distribuídos em oito torres e inclui áreas de lazer com playground, três espaços para festas, uma piscina para adultos e uma piscina infantil, três espaços para eventos com churrasqueiras e duas quadras para prática de esportes. De acordo com registros obtidos junto à portaria em 2013, havia 2.097 moradores no condomínio, sendo a ocupação atual equivalente a 665 apartamentos.

O número total de funcionários fixos que prestam serviços aos condôminos é de 558, equivalente a $84 \%$ de apartamentos ocupados com pelo menos uma funcionária doméstica. Devido às limitações do sistema de registro da portaria, não foi possível a identificação do número de funcionários por torre.

Quanto à questão da comunicação e acesso às informações pelos condôminos, há quadros de aviso localizados apenas nos elevadores sociais. Os condôminos também possuem acesso a uma página de internet e cadastro em rede social, onde estão disponíveis comunicados, informações variadas como atas de assembleias e reuniões do conselho, regulamento interno, convenção condominial e plantas baixas das áreas de garagens. 


\section{Gerenciamento dos resíduos sólidos domiciliares do condomínio}

O programa de coleta seletiva foi iniciado no ano de 2012 por problemas de ordem sanitária, causados pelo acúmulo de resíduos no depósito central do condomínio e, especialmente, também pela expectativa em adicionar receita ao empreendimento por meio da venda dos materiais recicláveis. Na negociação realizada entre o condomínio e o instituto responsável pela coleta dos recicláveis, um valor fixo obtido com a venda dos recicláveis foi repassado ao condomínio apenas nos primeiros meses de projeto. Após esse período, o proprietário do instituto afirmou não ser possível realizar mais repasses devido ao término do período de ocupação, quando eram obtidas maiores receitas em razão do descarte frequente de papelão proveniente de embalagens.

Segundo o regulamento interno, consta como responsabilidade de cada condômino o uso de sacos plásticos azuis pelos moradores para acondicionamento de materiais recicláveis, além do estabelecimento da obrigatoriedade de gerenciamento de resíduos volumosos e de construção civil gerados nas unidades.

Em relação à estrutura física e aos equipamentos disponíveis, há dois depósitos finais de resíduos, sendo um utilizado para o recebimento dos resíduos provenientes das torres e outro para armazenamento de recicláveis. Há oito depósitos intermediários para armazenamento temporário do resíduo até sua coleta, sendo disponível um depósito por torre. Os depósitos intermediários são equipados com um conjunto de três contentores de 420 litros cada, conforme demonstrado na Tabela 1.

\section{Coleta e depósitos de armazenamento final de resíduos}

Para a coleta dos resíduos nas torres, é utilizada uma motocicleta equipada com caçamba. Os resíduos de cada torre são coletados e transportados juntos e levados ao depósito final de armazenamento. A coleta nas salas de armazenamento de cada torre é realizada duas vezes ao dia, sendo a primeira às $8 \mathrm{~h}$ e a segunda no período da tarde, às $14 \mathrm{~h}$. As salas de armazenamento de recicláveis e não recicláveis localizam-se próximas entre si, em frente a uma das portarias de acesso para entrada e saída de veículos de moradores.

No depósito final de armazenamento ainda há muita mistura de recicláveis e não recicláveis nos sacos plásticos dispostos pelos moradores, e todas as sacolas são abertas para triagem pelos funcionários da empresa contratada para a separação dos materiais recicláveis. Os resíduos pré-selecionados seguem, posteriormente, para a sala de armazenamento de resíduos recicláveis, onde são segregados em diferentes categorias.

\section{METODOLOGIA}

\section{Avaliação do potencial de recuperação de resíduos}

Para avaliação do processo de recuperação de recicláveis foram comparadas as quantidades de resíduos recicláveis recuperados efetivamente em um período de seis meses em relação à quantidade de recicláveis presentes nos resíduos gerados no condomínio.

A quantidade de resíduos gerados foi registrada por meio da contagem do número de viagens realizada pelo veículo coletor do condomínio nas torres, registrados pelos funcionários do condomínio que realizam a limpeza durante a terceira semana do mês de agosto de 2013. A capacidade de transporte do veículo foi obtida de acordo com a Equação 1 e o volume da caçamba do veículo coletor de acordo com a Equação 2:

Volume resíduo $\left(\mathrm{m}^{3}\right) /$ torre $=\left(\mathrm{n}^{\mathrm{o}}\right.$ viagens $/$ torre $) \times$ vol. veículo $\left(\mathrm{m}^{3}\right)$

$\mathrm{V}=1,6 \mathrm{~m} \times 1,0 \mathrm{~m} \times 0,8 \mathrm{~m}=1,28 \mathrm{~m}^{3}$

Como o município de São Caetano do Sul não dispõe de estudo gravimétrico (SÃO CAETANO DO SUL, 2013), foi utilizado como referência o estudo de gravimetria de resíduos sólidos urbanos de regiões de alto índice de verticalização do município de São Paulo (MORAES,

Tabela 1 - Levantamento dos locais intermediários de armazenamento.

\begin{tabular}{|c|c|c|c|c|c|c|c|}
\hline \multirow{2}{*}{ Torre } & \multirow{2}{*}{ Área apto. $\left(\mathrm{m}^{2}\right)$} & \multirow{2}{*}{ Aptos/torre } & \multirow{2}{*}{ No moradores } & \multirow{2}{*}{$\begin{array}{c}\mathrm{N}^{\mathrm{O}} \text { moradores/ } \\
\text { apto. }\end{array}$} & \multirow{2}{*}{$\begin{array}{l}\text { Área dos depósi- } \\
\text { tos de resíduos } \\
\text { das torres }\left(\mathrm{m}^{2}\right)\end{array}$} & \multicolumn{2}{|c|}{$\mathrm{N}^{\circ}$ contentores $\left(0,42 \mathrm{~m}^{3}\right)$} \\
\hline & & & & & & Recicláveis & Não recicláveis \\
\hline 01 & \multirow{2}{*}{182} & 50 & 183 & 3,7 & 3,6 & 2 & 1 \\
\hline $\mathrm{O} 2$ & & 50 & 164 & 3,3 & 6,2 & 2 & 1 \\
\hline $\mathrm{O} 3$ & \multirow{2}{*}{146} & 100 & 369 & 3,7 & 4,6 & 2 & 1 \\
\hline O4 & & 100 & 409 & 4,1 & 23,0 & 2 & 1 \\
\hline 05 & \multirow{2}{*}{128} & 100 & 330 & 3,3 & 17,0 & 2 & 1 \\
\hline 06 & & 100 & 289 & 2,9 & 13,5 & 2 & 1 \\
\hline 07 & \multirow{2}{*}{97} & 100 & 295 & 2,9 & 6,4 & 2 & 1 \\
\hline 08 & & 100 & 255 & 2,6 & 6,4 & 2 & 1 \\
\hline
\end{tabular}


2003), conforme mostrado na Tabela 2. Este estudo foi utilizado como referência devido à similaridade comportamental das populações dos municípios de São Paulo e de São Caetano do Sul.

Assim, conforme a Tabela 2, os recicláveis com potencial de comercialização e envio para reciclagem, obtidos a partir de Moraes (2003), representariam $37,8 \%$ em relação ao resíduo domiciliar total gerado. Os recicláveis recuperados pelo processo de triagem no condomínio foram quantificados por meio de boleto de pesagem emitido pela balança no momento da venda dos resíduos às empresas compradoras de recicláveis.

Para a quantificação dos resíduos totais gerados diariamente no condomínio em massa $(\mathrm{RDO} \mathrm{PC}=$ resíduos domiciliares gerados pelo condomínio), foi realizado o levantamento do volume de resíduos gerados por dia para todas as torres, multiplicado pela densidade aparente dos resíduos sólidos domiciliares de $216 \mathrm{~kg} / \mathrm{m}^{3}$, dada por Moraes (2003), e calculado conforme a Equação 3:

RDO PC $(\mathrm{kg} / \mathrm{dia})=$ volume resíduos gerados $\left(\mathrm{m}^{3} / \mathrm{dia}\right) \times 216\left(\mathrm{~kg} / \mathrm{m}^{3}\right)$

A massa dos resíduos secos recuperados do condomínio foi relacionada à quantidade potencialmente presente de recicláveis nos resíduos, utilizando-se as informações da Tabela 2 e da Equação 3, considerando-se assim a eficiência da coleta seletiva do condomínio de abril a setembro de 2013, conforme o cálculo demonstrado na Equação 4:

Eficiência $(\%)=\frac{\text { massa dos resíduos secos recuperados do condomínio }(\mathrm{kg} / \mathrm{dia})}{37,8 \% \times \text { RDO PC }(\mathrm{kg} / \mathrm{dia})}$

\section{Entrevista com as partes envolvidas no programa de coleta seletiva}

Foram realizadas entrevistas semiestruturadas com o proprietário da empresa de triagem e coleta e com o integrante do Conselho Diretivo do condomínio responsável pela implantação do programa, ambas sobre as principais barreiras existentes no empreendimento.

Também foi aplicado um questionário aos moradores, conforme apresentado na Figura 1. O questionário foi aplicado nos meses de julho e agosto de 2014, por meio de sua colocação nas caixas de correio dos moradores, selecionando-se aleatoriamente 25 unidades em cada uma das 8 torres, correspondente a 200 apartamentos.

Tabela 2 - Composição gravimétrica dos Resíduos Sólidos Urbanos do município de São Paulo.

\begin{tabular}{l|c} 
Resíduos & $\begin{array}{c}\text { Percentual } \\
\text { em massa }\end{array}$ \\
\hline 1. Recicláveis (metal, papel, plástico, longa vida, vidro) & $37,8 \%$ \\
\hline $\begin{array}{l}\text { 2. Não recicláveis (tecidos, resíduos tecnológicos } \\
\text { diversos, matéria orgânica, embalagens aluminadas) }\end{array}$ & $62,2 \%$ \\
\hline
\end{tabular}

Fonte: Moraes (2003)

\section{RESULTADOS E DISCUSSÃO}

\section{Avaliação da gestão de resíduos no condomínio}

A Tabela 3 mostra os volumes de resíduos gerados por dia no condomínio, bem como número de unidades e a área referente aos apartamentos de cada torre.

Em relação à coleta dos resíduos gerados, verificou-se que é maior o volume de resíduo coletado no período da manhã em relação ao resíduo coletado após as $14 \mathrm{~h}$, provavelmente devido ao intervalo de coleta ser menor entre às $8 \mathrm{~h}$ e às $14 \mathrm{~h}$, e também em decorrência do maior volume gerado após às $18 \mathrm{~h}$, quando a maior parte da população está em suas residências, e por coincidir com a saída dos funcionários domésticos ao final da tarde, por volta das $16 \mathrm{~h}$.

Por meio da análise do levantamento realizado, verificou-se que, próximo aos locais de armazenamento de resíduos, estão as salas denominadas DML (depósito de material de limpeza), locais em que são armazenados os carrinhos de limpeza utilizados pelos funcionários do condomínio. Para armazenamento de produtos de limpeza, esses encontram-se centralizados nos DML das torres 5 e 6.

\section{Avaliação dos resultados da recuperação de recicláveis}

Dentre os materiais recicláveis recuperados em massa no período de seis meses do estudo, nota-se a predominância do papel (58\%), seguido por plástico (24\%), vidro (13\%) e metais ferrosos e não ferrosos (alumínio), que totalizam $5 \%$. A Tabela 4 mostra a quantidade média, em quilogramas, de materiais recicláveis retirados comercializáveis por viagem realizada dentro do condomínio no período estudado, de abril a setembro de 2013.

Uma vez que os resultados obtidos são reflexo da eficiência do processo de triagem realizado na área de armazenamento final, bem como da participação de moradores na segregação e limpeza dos recicláveis, é possível avaliar os seguintes itens:

- a eficiência do programa de coleta seletiva com o processo de triagem dos resíduos sólidos domiciliares (RDO) implementado;

- número equivalente de apartamentos que estariam participando efetivamente do programa, caso não houvesse complementação de atividades pelo processo de triagem.

Para calcular a eficiência no processo de recuperação de recicláveis, utilizou-se como referência o percentual de recicláveis presentes nos resíduos domiciliares de $37,8 \%$ e massa específica de $216 \mathrm{~kg} / \mathrm{m}^{3}$, conforme proposto por Moraes (2003).

A Tabela 5 apresenta a recuperação de materiais recicláveis pelo condomínio e o potencial máximo de recuperação de resíduos sólidos recicláveis secos.

Assim, a eficiência obtida na recuperação de recicláveis presentes no RDO do condomínio é de 13,7\%, valor que corresponderia, em média, a 91 apartamentos participantes dentre os 665 apartamentos ocupados. 


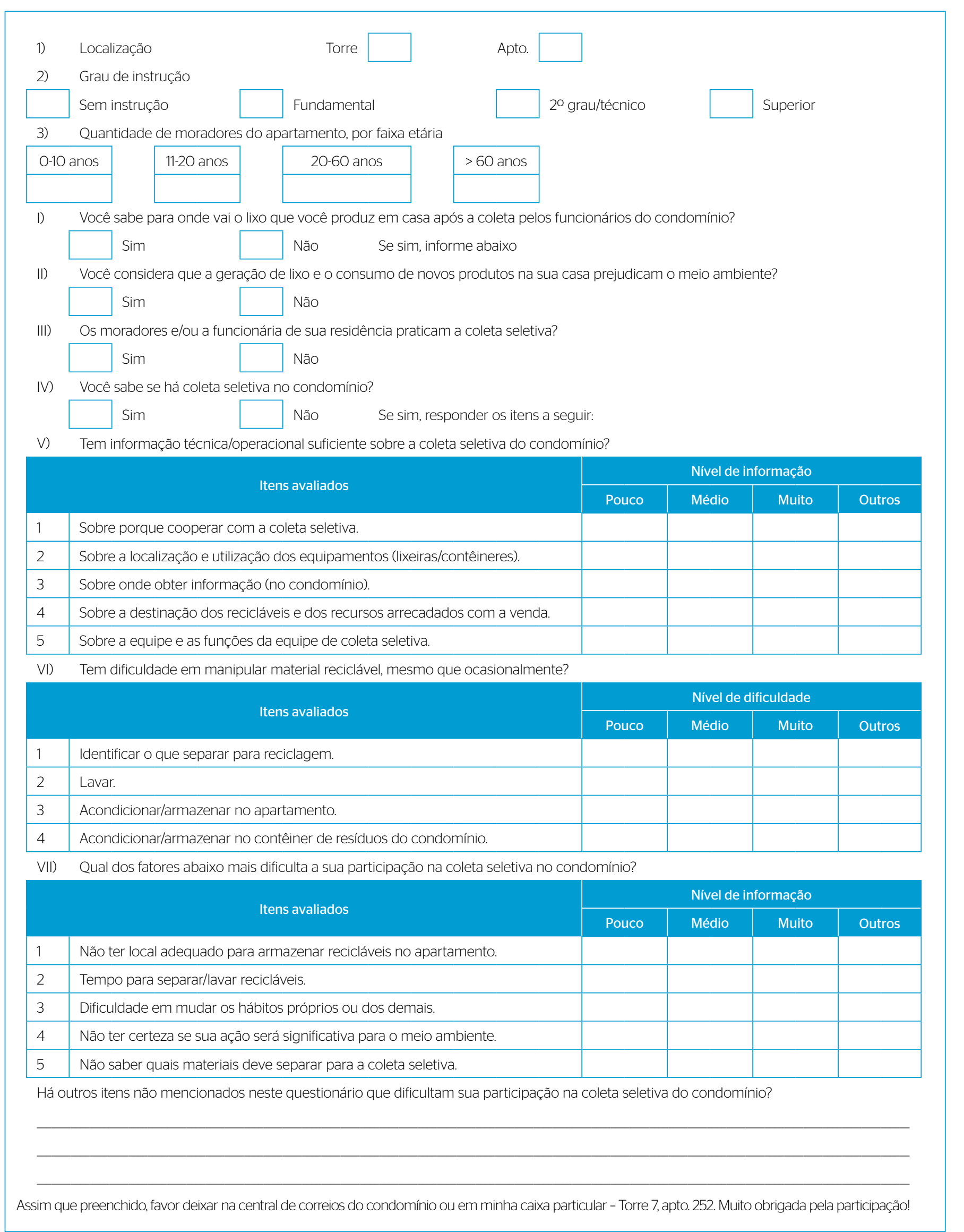

Figura 1 - Modelo do questionário aplicado aos moradores do condomínio. 


\section{Aplicação do questionário}

Dentre os 200 questionários entregues aos condôminos de maneira aleatória, foram obtidas 101 respostas, o equivalente a cerca de $50 \%$ dos apartamentos contatados e $15 \%$ do total de apartamentos, as quais seguem discriminadas por torre, conforme a Tabela 6.

Em relação à pergunta "Você sabe para onde vai o resíduo que você produz em casa após a coleta pelos funcionários do condomínio?", apenas $6 \%$ responderam afirmativamente, sendo assim, $94 \%$ não sabem qual é o destino dos resíduos após a coleta pelos funcionários do condomínio. O resultado evidencia o distanciamento em relação às consequências ao meio ambiente do comportamento em termos do manuseio dos resíduos realizado por cada indivíduo.

Em relação à pergunta "Você considera que a geração de resíduos e o consumo de novos produtos na sua casa prejudicam o meio ambiente?", $75 \%$ dos respondentes afirmaram que o consumo de novos produtos prejudica o meio ambiente. Assim, 25\% ou um quarto dos respondentes não vinculam o consumo de novos produtos com impacto ao meio ambiente. Isto representa um alto percentual de respondentes que não estão sensíveis às questões atuais presentes dentre as prioridades estabelecidas na Política Nacional de Resíduos Sólidos, as quais determinam como prioridade a não geração de resíduos como fator primordial para a gestão sustentável de resíduos sólidos. Eventualmente, ao mesmo tempo, pode significar que há uma visão equivocada de que a coleta seletiva e a reciclagem podem ser suficientes para mitigar o impacto do consumo de novos produtos e o aumento da geração de resíduos.

Em relação à pergunta "Os moradores e/ou a funcionária da sua residência praticam a coleta seletiva?" todos os respondentes afirmaram praticar a coleta seletiva. É razoável relacionar o resultado obtido a respondentes com "bom comportamento" em termos de coleta seletiva, ou seja, condôminos que realizaram o esforço de responder ao questionário são mais propensos a estarem comprometidos com a coleta seletiva do que aqueles que não responderam, afinal, segundo a Tabela 5, apenas $13,7 \%$ é recuperado. Essa conclusão é suportada pelo fato de que a totalidade dos respondentes afirma que participa da coleta seletiva.

Em relação à pergunta "Você sabe se há coleta seletiva no condomínio?", todos os respondentes afirmaram saber de sua existência. Esse resultado mostra que é de conhecimento dos condôminos entrevistados a existência de um programa de coleta seletiva no condomínio.

Tabela 3 - Volume de resíduos gerados no condomínio, considerando disponíveis três contentores de 420 litros por torre para armazenamento.

\begin{tabular}{|c|c|c|c|c|c|}
\hline Torres & Área apto. $\left(\mathrm{m}^{2}\right)$ & No aptos. & No moradores & Volume resíduos ( $\left.\mathrm{m}^{3} / \mathrm{dia}\right)$ & Litros/morador/dia \\
\hline $\mathrm{T} 1$ & 182 & 50 & 174 & 1,3 & 7,5 \\
\hline $\mathrm{T} 2$ & 182 & 50 & 156 & 1,3 & 8,3 \\
\hline T3 & 146 & 100 & 351 & 2,6 & 7,4 \\
\hline $\mathrm{T} 4$ & 146 & 100 & 305 & 2,6 & 8,5 \\
\hline T5 & 128 & 100 & 314 & 2,6 & 8,3 \\
\hline T6 & 128 & 100 & 274 & 2,6 & 9,5 \\
\hline $\mathrm{T7}$ & 97 & 100 & 280 & 1,9 & 6,8 \\
\hline T8 & 97 & 100 & 242 & 1,9 & 7,9 \\
\hline Total & & 700 & 2.097 & 16,8 & 64,2 \\
\hline
\end{tabular}

Tabela 4 - Quantidade de materiais recicláveis retirados comercializáveis em kg.

\begin{tabular}{l|c|c|c|c|c|c|c|c|c}
\hline Material/periodo & abr/13 & maio/13 & jun/13 & jul/13 & ago/13 & set/13 & No retiradas & Total (kg) & $\mathrm{kg} /$ retirada \\
\hline Plástico filme & 300 & - & 190 & 228 & 230 & - & 4 & 948 & 237 \\
\hline Sacolinhas & 420 & - & - & 450 & 230 & 210 & 4 & 1.310 & 328 \\
\hline PET & 720 & - & 241 & 392 & 320 & 210 & 5 & 1.883 & 377 \\
\hline PP & 380 & - & 121 & 442 & 422 & 231 & 5 & 1.596 & 319 \\
\hline PEAD & 440 & - & 135 & 270 & 366 & 180 & 5 & 1.391 & 278 \\
\hline Plástico misto & 360 & - & 220 & 240 & 219 & - & 4 & 1.039 & 260 \\
\hline Vidro & 980 & - & 945 & 930 & 410 & 1.010 & 5 & 4.275 & 855 \\
\hline Alumínio & 400 & - & - & - & 320 & - & 2 & 720 & 360 \\
\hline Metal ferroso & - & - & - & - & 1.000 & - & 1 & 1.000 & 1.000 \\
\hline Papelão & 1.990 & 2.090 & 1.950 & 2.100 & 2.700 & 920 & 6 & 11.750 & 1.958 \\
\hline Papel misto & 1.250 & 1.700 & 1.490 & 1.200 & 730 & 530 & 6 & 6.900 & 1.150 \\
\hline Papel branco & - & - & - & 400 & - & 420 & 2 & 820 & 410 \\
\hline Total & 7.240 & 3.790 & 5.292 & 6.652 & 6.947 & 3.711 & 49 & 33.632 & 686 \\
\hline
\end{tabular}

PET: politereftalato de etileno; PP: polipropileno; PEAD: polietileno de alta densidade. 
Sobre a disponibilidade de informações técnicas e operacionais a respeito do programa, foram abordados cinco aspectos relacionados a essa disponibilidade, conforme mostra a Figura 2.

Verificou-se que, de forma geral, apresentaram-se deficitários os aspectos relacionados às informações veiculadas quanto à equipe e às suas funções em relação à coleta seletiva, à destinação de recicláveis e aos recursos provenientes da comercialização dos recicláveis, bem como quanto aos locais com informações disponíveis sobre o programa no condomínio.

Quanto aos aspectos avaliados sobre o acesso às informações sobre o porquê cooperar com a coleta seletiva no condomínio, o percentual resultante da somatória entre "médio" e "muito" foi equivalente a $88 \%$, e informações sobre a localização e a utilização de lixeiras foram considerados igualmente satisfatórios, com resultado de $94 \%$.

Sobre os aspectos relacionados à dificuldade na manipulação dos materiais recicláveis, os resultados são apresentados Figura 3.

Ao analisar a Figura 3, verifica-se que apenas o aspecto de "acondicionar no contentor de cada torre" não corresponde a um nível significativo de dificuldade quanto à participação do programa de coleta

Tabela 5 - Cenário real e potencial de coleta seletiva de resíduos recicláveis comercializáveis no condomínio estudado.

\begin{tabular}{l|c|c}
\hline Número de condôminos & \multicolumn{2}{|c}{2.097} \\
\hline RDO PC (m³/dia) & \multicolumn{2}{|c}{16,64} \\
\hline Massa específica RDO (kg/m³) & \multicolumn{2}{|c}{31694,24} \\
\hline RDO (kg/dia) & \multicolumn{2}{|c}{1,71} \\
\hline RDO per capita & \multicolumn{2}{|c}{37,8} \\
\hline \% recicláveis considerada & \multicolumn{2}{|c}{33.632} \\
\hline $\begin{array}{l}\text { Recicláveis comercializados no } \\
\text { condomínio de abril a setembro } \\
\text { de 2O13 (kg) }\end{array}$ & Recuperação & Recuperação \\
\hline & 186,78 & real \\
\hline Recicláveis (kg/dia) & 0,088 & $0,648,62$ \\
\hline Recicláveis (kg/dia/condômino) & $13,7 \%$ & $100,0 \%$ \\
\hline \% recicláveis recuperados & \multicolumn{2}{|c}{} \\
\hline
\end{tabular}

RDO PC: resíduos domiciliares gerados pelo condomínio; RDO: resíduos domiciliares gerados

Tabela 6 - Respostas aos questionários obtidas por torre.

\begin{tabular}{c|c|c|c} 
Torre & $\begin{array}{c}\text { Número de } \\
\text { questionários } \\
\text { entregues }\end{array}$ & $\begin{array}{c}\text { Número respostas } \\
\text { obtidas }\end{array}$ & $\begin{array}{c}\text { Percentual de } \\
\text { participação } \\
\text { por torre }\end{array}$ \\
\hline T1 & 25 & 9 & $36 \%$ \\
\hline T2 & 25 & 7 & $28 \%$ \\
\hline T3 & 25 & 13 & $52 \%$ \\
\hline T4 & 25 & 14 & $56 \%$ \\
\hline T5 & 25 & 10 & $40 \%$ \\
\hline T6 & 25 & 9 & $36 \%$ \\
\hline T7 & 25 & 19 & $76 \%$ \\
\hline T8 & 25 & 20 & $80 \%$ \\
\hline Total & 200 & 101 & $50 \%$ \\
\hline
\end{tabular}

seletiva. Os demais, somando-se as classificações "muito" e "médio", apresentam mais de $50 \%$ de entrevistados que pontuaram como fatores de dificuldade, sendo o mais significante o aspecto de identificar o que separar para reciclagem, o qual está em torno de 56\%.

Sobre os aspectos que afetam negativamente a motivação em participar do programa, as respostas sobre os cinco itens consultados são apresentadas na Tabela 7, que também mostra uma classificação em ordem decrescente sobre a somatória obtida entre os percentuais correspondentes a "muito" e "médio".

O resultado dos aspectos avaliados indica que a ausência de local adequado para armazenamento de recicláveis no apartamento, correspondente a $56 \%$, é o item que mais impacta negativamente o aproveitamento de recicláveis pelo condomínio. Em segundo lugar estão os motivos relacionados ao tempo para lavar os recicláveis e a dificuldade para mudar hábitos próprios e dos demais. Como fatores que impactam de forma menos significativa estão, respectivamente, $o$ fato de os condôminos não saberem quais materiais devem ser separados para a coleta seletiva (25\%) e não terem certeza se a ação empregada será significativa para o meio ambiente (12\%).

\section{Entrevistas com envolvidos no programa de coleta seletiva}

Foram realizadas entrevistas com o representante do Conselho Diretivo responsável pela coleta seletiva no condomínio e com o instituto responsável pela recuperação de recicláveis a respeito de fatores que favorecem e que bloqueiam o desenvolvimento do programa de coleta seletiva. As respostas dos entrevistados são descritas nos tópicos a seguir.

\section{Entrevista com conselheiro diretivo responsável pelo programa de coleta seletiva no condomínio}

1) Quais são as expectativas em relação à implantação do programa? Verificou-se que a principal expectativa da coordenação do programa da coleta seletiva é a obtenção de retorno financeiro para o condomínio. Assim, questões ambientais ou a reputação do condomínio não estão, no momento, dentre as prioridades do programa.

O representante do Conselho reconhece todas as dificuldades e os esforços feitos pelo instituto quanto ao programa de recuperação de recicláveis no condomínio e, inclusive, havia planejado uma proposta inicial de atuação do instituto na educação ambiental em reuniões do condomínio, com vistas a estimular a participação dos moradores. Entretanto, ao avaliar o material a ser apresentado pelo instituto quanto à clareza e à objetividade, e dado especialmente ao fato de que as assembleias e as reuniões no referido condomínio serem demoradas e dispendiosas devido ao elevado número de condôminos, decidiu-se que o tema não estava suficientemente adequado para apresentação no momento. 


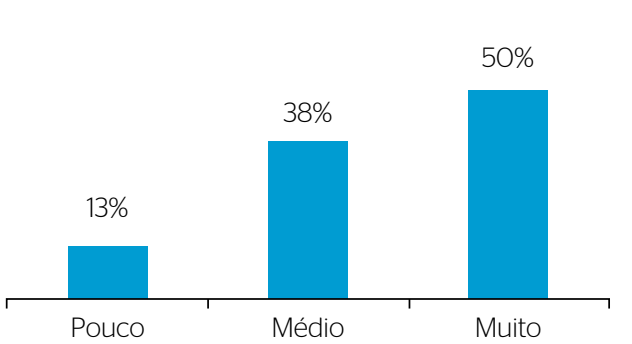

a) Informações sobre porque cooperar com a coleta seletiva.

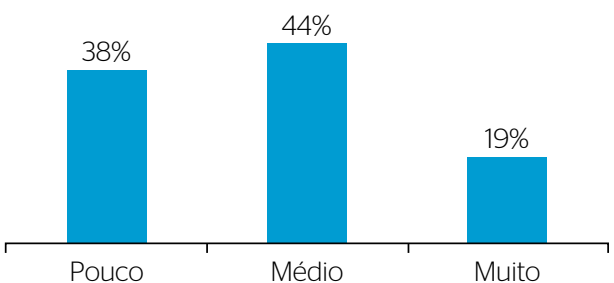

c) Informações sobre onde obter informação (no condomínio).

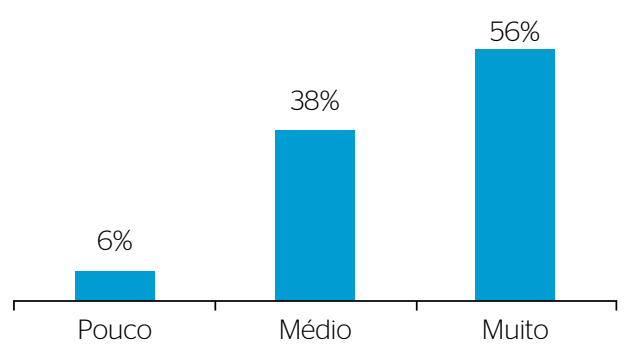

b) Informações sobre a localização e a utilização lixeiras/contêineres.

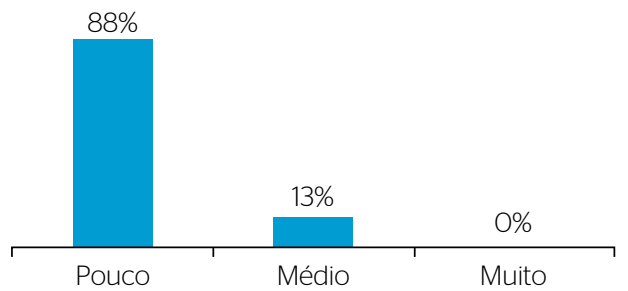

d) Informações sobre a destinação dos recicláveis e dos recursos.

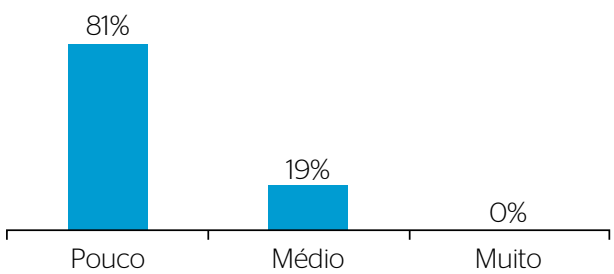

e) Informações sobre a equipe e suas funções na coleta seletiva.

Figura 2 - Resultados da aplicação do questionário sobre o nível de informação a respeito do programa de coleta seletiva do condomínio estudado.

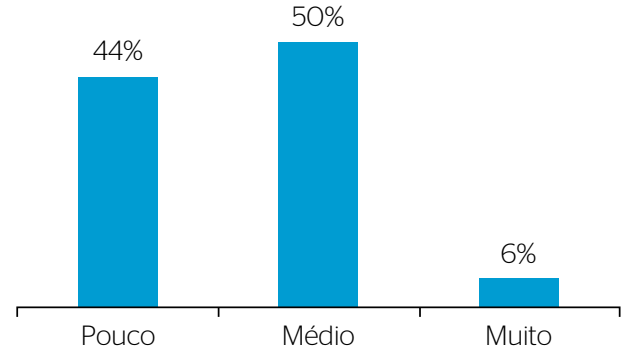

a) Identificar o que separar para reciclagem.

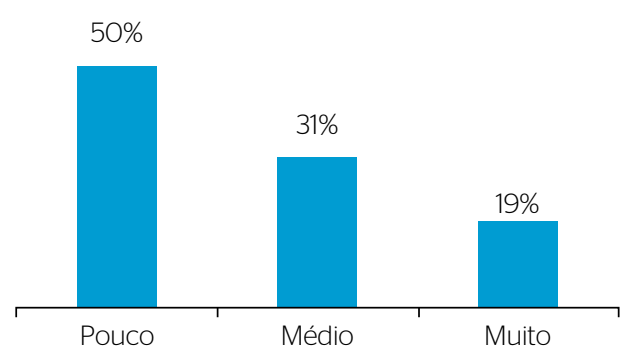

c) Acondicionar/armazenar no apartamento.

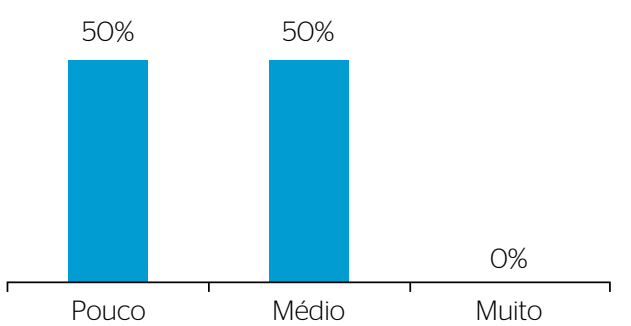

b) Lavagem dos materiais recicláveis antes do descarte.

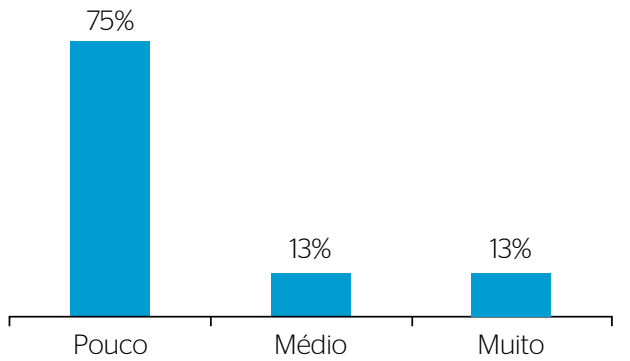

d) Acondicionar/armazenar no contentor de resíduos das torres.

Figura 3 - Resultados da aplicação do questionário sobre o nível de informação sobre os aspectos relacionados à dificuldade na manipulação dos materiais recicláveis. 
Tabela 7 - Classificação das respostas obtidas sobre o que mais afeta negativamente a motivação para participar no programa.

\begin{tabular}{|c|c|c|c|c|}
\hline Classificação & Aspectos avaliados & Pouco & Médio & Muito \\
\hline 10 & Não ter local adequado para armazenar recicláveis no apartamento. & $44 \%$ & $18 \%$ & $38 \%$ \\
\hline 20 & Dificuldade em mudar os hábitos próprios e dos demais. & $50 \%$ & $44 \%$ & $6 \%$ \\
\hline 30 & Tempo para separar/lavar recicláveis. & $50 \%$ & $50 \%$ & ०\% \\
\hline $4^{\circ}$ & Não saber quais materiais deve separar para a coleta seletiva. & $75 \%$ & $25 \%$ & O\% \\
\hline 50 & Não ter certeza se sua ação será significativa para o meio ambiente. & $88 \%$ & O\% & $12 \%$ \\
\hline
\end{tabular}

\section{2) Quanto aos investimentos necessários no programa.}

Não está previsto investimento no programa, mesmo que esse seja pago ao longo do período de um ano pela comercialização de resíduos. Exceção feita em relação à necessidade de organização da área interna nas torres para melhorias de questões sanitárias do armazenamento dos resíduos.

\section{3) Fatores significativos que dificultam o processo.}

Foi identificada pelo representante do Conselho do condomínio a ausência de um programa formal, devidamente estruturado, dado aos esforços requeridos para implantação em uma estrutura de grande porte, capaz de envolver o elevado número de moradores presentes.

Além disso, ele citou a dificuldade no condomínio em relação à mudança de destinação de utilização de um determinado local, o qual, conforme convenção, necessita da aprovação da totalidade dos condôminos para ser realizada, bem como das despesas associadas.

\section{Entrevista com responsável pelo instituto}

Em entrevista com o instituto responsável pela coleta, obtiveram-se as seguintes respostas:

\section{1) Expectativas em relação à implantação do programa.}

Verificou-se que a principal expectativa do instituto é realizar um projeto de recuperação de recicláveis de sucesso, aliado à sustentabilidade financeira da atividade.

Há inúmeras propostas de implantação de boas práticas relacionadas ao desvio de resíduos para aterro, inclusive práticas sociais como doação de roupas e de objetos usados, produtos de higiene em bom estado para albergues e coleta de óleo de cozinha. Além disso, o instituto realiza o transporte de lâmpadas para pontos de entrega, coleta de resíduos de madeira (em menores volumes) e destinação de eletrônicos para o condomínio.

\section{2) Quanto aos investimentos necessários no programa.}

No momento, o instituto não prevê investimento no programa e considera que o investimento necessário é de responsabilidade do condomínio.

\section{3) Fatores significativos que dificultam o processo.}

A triagem inadequada de recicláveis e não recicláveis, por parte de moradores, nas áreas de armazenamento intermediárias foi identificada como o maior impacto e risco existente para a operação, devido ao tempo despendido para pré-selecionar o resíduo, e o risco da presença de materiais cortantes ou infectados.

A ausência de um programa formal, devidamente estruturado para o condomínio, foi relatado como aspecto significativo, especialmente quanto à falta de comunicação e de conscientização dos moradores. Foi relatado que se esperam ações do condomínio quanto à adequação do programa de coleta seletiva, a fim de que não seja necessário realizar triagem em todo o volume de resíduo gerado.

\section{CONCLUSÕES}

Verificou-se por meio dos resultados obtidos que a recuperação de recicláveis no condomínio estudado corresponde a 13,7\% do potencial de recicláveis presentes nos resíduos domiciliares, o que equivale a 91 apartamentos participantes efetivos dentre os 665 apartamentos ocupados.

Esse número evidencia um baixo índice de recuperação dado ao potencial existente no condomínio quanto à produção potencial de recicláveis pelos moradores, que possuem características ligadas a um alto poder de compra, e eventualmente às características do condomínio, que favorece a permanência e o desenvolvimento de atividades sociais pelos moradores internamente, o que contribuiu para a geração de recicláveis no condomínio.

Os dados obtidos com o monitoramento contínuo de recuperação, a produção mensal de recicláveis e a sistematização das entrevistas apontam, de forma geral, que é necessário incentivar e promover o envolvimento e a participação dos moradores, buscando resultados quanto à mudança de comportamento, atitudes e hábitos.

Nesse sentido, as prefeituras possuem papel importante quanto à implantação de políticas públicas e ações de estímulo para a participação social, uma vez que a coleta seletiva de resíduos sólidos domiciliares em condomínios sofre com a ausência ou a descontinuidade de 
ações efetivas de divulgação e de mobilização, da infraestrutura e de decisões da administração local.

Verifica-se que é fundamental garantir um canal permanente de informação com os moradores dos condomínios, divulgando os resultados obtidos, orientando e incentivando a participação dos moradores no programa.

No condomínio estudado foram identificadas as seguintes dificuldades:

- falta de um programa estruturado, que inclua comunicação, como informações sobre como separar os recicláveis e a importância dessa ação, e divulgação de resultados alcançados;

- o elevado número de apartamentos existente traz como consequência a necessidade de esforços extras com a comunicação, sendo que campanhas porta-a-porta, por exemplo, incorreriam em maiores custos. O elevado número de unidades envolvidas e a rotatividade de moradores trazem também uma característica de certa forma mais impessoal ao condomínio, que torna a influência de um vizinho sobre o outro quanto à participação no programa mais difícil ou eventualmente inexistente. Por outro lado, essa maior escala possibilita economia na infraestrutura preparada para a coleta seletiva;

- a falta do envolvimento contínuo de funcionários domésticos de uma forma específica no programa, uma vez que eles estão presentes na grande maioria dos apartamentos.

Como aspectos positivos a serem fortalecidos, identificaram-se:

- potencial de geração elevada de recicláveis, de forma concentrada, permitindo boas possibilidades de comercialização e obtenção de receita;

- opção de armazenamento de recicláveis no mesmo local de armazenamento de não recicláveis nas torres, o que propicia comodidade e funcionalidade aos moradores;
- possibilidade de destinação dos recicláveis a qualquer momento, não sendo necessário obedecer a horários e dias determinados de coleta de recicláveis, contribuindo novamente com aspectos de comodidade; - facilidade de operação da atividade de triagem, dada à disponibilidade de áreas de armazenamento de recicláveis e não recicláveis de forma segregada nas torres, bem como estoque de grandes quantidades de recicláveis em locais de fácil acesso ao logradouro no condomínio para retirada e transferência para caminhões;

- localização do condomínio em região com atividade industrial elevada.

Diante do estudo realizado, pode-se verificar que mesmo com os todas as condições favoráveis e oportunidades existentes e, até mesmo sendo uma necessidade, a coleta seletiva precisa de fortes incentivos por parte dos gestores, a fim de que haja maior participação no processo, especialmente quanto a iniciativas que promovam o envolvimento de moradores, ação que se constatou como sendo o grande desafio a ser realizado dentre as etapas existentes no programa.

Em entrevista com o membro do conselho responsável pelo programa, o fator de motivação inicial foi a expectativa com incremento de receita ao condomínio, identificada durante a fase inicial de ocupação pela presença de grande volume de resíduos comercializáveis, especialmente o papelão.

Assim, para que seja possível o sucesso do programa, recomenda-se redefinir o plano de coleta seletiva em andamento, incluindo a oportunidade de participação dos moradores, com sugestões, e garantindo sua implantação.

Sugere-se a contratação de uma consultoria como suporte para esse desenvolvimento, reunião para discussão e validação entre as partes - Conselho Diretivo, instituto e consultoria para fechamento final entre o Conselho Diretivo e a consultoria -, seguido finalmente para a implantação.

\section{REFERÊNCIAS}

ASSOCIAÇÃO BRASILEIRA DE EMPRESAS DE LIMPEZA PÚBLICA E RESÍDUOS ESPECIAIS - ABRELPE. (2012) Panorama dos Resíduos Sólidos no Brasil 2012. São Paulo. 116p.

BRASIL. (2010) Lei Federal n 12.305, de 2 de agosto de 2010. Institui a Política Nacional de Resíduos Sólidos; altera a Lei no 9.605, de 12 de fevereiro de 1998; e dá outras providências. Presidência da República, Casa Civil, Diário Oficial da União, Brasília, DF, 3 ago. 2010

COMPROMISSO EMPRESARIAL PARA RECICLAGEM - CEMPRE. (2010) Lixo municipal: manual de gerenciamento integrado. 3. ed São Paulo.

CONSELHO BRASILEIRO DE CONSTRUÇÃO SUSTENTÁVEL (CBCS); SINDICATO DA HABITAÇÃO (SECOVI). (2011) Condutas de sustentabilidade do setor imobiliário residencial. Disponível em: <http://www.cbcs.org.br/userfiles/ download/CadernoCondutasDeSustentabilidade.pdf>. Acesso em: 5 nov. 2013.

INSTITUTO DE PESQUISAS ECONÔMICAS E APLICADA - IPEA. (2012) Diagnóstico dos Resíduos Sólidos Urbanos. Relatório de Pesquisa. Brasília: IPEA. 77 p.

MORAES, T. (Coord). (2003) Caracterização gravimétrica e físicoquímica dos resíduos sólidos domiciliares do município de São Paulo. São Paulo: PMSP/Limpurb. 133 p.

SÃO CAETANO DO SUL. DEPARTAMENTO DE AGUA E ESGOTO. (2013) Plano de gestão integrada de resíduos sólidos de São Caetano do Sul. São Caetano do Sul. Disponível em: <http://www. saocaetanodosul.sp.gov.br/pdfs/planos/pgirs_scs_apresentacao_ final.pdf>. Acesso em: 10 nov. 2013. 